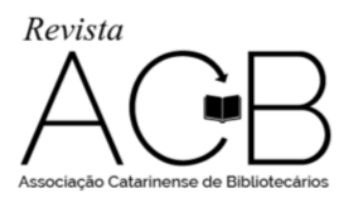

O uso de relatórios anuais de atividades como instrumento de avaliação do acervo das bibliotecas que compõem o Núcleo Integrado de Bibliotecas a Universidade Federal do Maranhão no período de 2008 a 2012 - Cláudia Maria Pinho de Abreu Pecegueiro e Alessandra Gomes Melo Aguiar Freitas

\title{
O USO DE RELATÓRIOS ANUAIS DE ATIVIDADES COMO INSTRUMENTOS DE AVALIAÇÃO DO ACERVO DAS BIBLIOTECAS QUE COMPÕEM O NÚCLEO INTEGRADO DE BIBLIOTECAS DA UNIVERSIDADE FEDERAL DO MARANHÃO NO PERÍODO DE 2008 a 2012
}

\author{
Cláudia Maria Pinho de Abreu Pecegueiro ${ }^{1}$ \\ gm.alessandra@hotmail.com \\ Alessandra Gomes Melo Aguiar Freitas ${ }^{2}$ \\ claudia.pecegueiro@ufma.br
}

\begin{abstract}
Resumo: Estudo sobre o relatório como ferramenta de gestão capaz de servir como instrumento de avaliação de atividades. Objetiva identificar, através da análise derelatórios Anuais de atividades do Núcleo Integrado de bibliotecas da Universidade Federal do Maranhão (NIB/UFMA), se este oferece informações suficientes para auxiliar no processo deavaliação e Planejamento das bibliotecas do NIB/UFMA no setor acervo no período de 2008 a 2012. Utiliza como metodologia a pesquisa Documental, bem como a pesquisa Bibliográfica. Conclui observando que os relatórios Anuais de Atividades do NIB/UFMA são importantes fontes de informação, porém, muito superficiais, impossibilitando uma maior compreensão dos dados.
\end{abstract}

Palavras-chave: Gestão de bibliotecas. Biblioteca Universitária. Relatório. Universidade Federal do Maranhão.

\section{INTRODUÇÃO}

A compreensão do conceito "Sociedade da Informação" está diretamente relacionada ao novo período em que a humanidade vive onde o fluxo das informações disponíveis é muito maior do que outrora imaginável. Este volume informacional vem trazendo consideráveis mudanças nos diversos cenários que compõem a vida humana, inclusive no que tange à dinâmica das organizações, o que pode caracterizarsucesso ou fracasso dentro do seu corpo funcional de acordo com o seu uso, e, para que estas informações possam ser colhidas e eficientemente utilizadas, é exigido um novo comportamento por parte dos gestores que devem buscar a sistematização e a integração dos processos para que a organização possa ser vista em sua totalidade.

Desta forma, entende-se que para alcançar os ideais de realização de ações decisórias a partir da coleta de informações é necessário avaliar o desempenho das organizações para o aprimoramento de suas atividades tornando-se implícita a aplicação de um conjunto de técnicas e habilidades, fundamentadas pelo Planejamento.

Ao analisar a biblioteca Universitária (B.U) como uma organização formal diretamente ligada à Universidade, são reconhecidos seus processos administrativos, principalmente no que tange ao seu Planejamento, avaliação e a elaboração de relatórios como ferramentas capazes de auxiliar o(s) Bibliotecário(s) gestor(es) na tomada de decisões.A partir da análise dos relatórios de gestão do NIB/UFMA, emergem questões relacionadas ao Planejamento, avaliaçãoe a consequente elaboração de relatórios nas Unidades de Informação, tais como:osrelatórios Anuais de atividades do Núcleo Integrado de bibliotecas da Universidade Federal do Maranhão (NIB/UFMA) podem servir como ferramentas para avaliar as atividadesrealizadas no acervo das bibliotecas que o compõem? Até que ponto as informações contidas nos relatórios de gestão do NIB/UFMApodem auxiliar no processo de Planejamento do Núcleo?

O objetivo deste estudo está em analisar os dados mensurados por meio dos relatórios Anuais de Atividades do Núcleo Integrado de bibliotecas da Universidade Federal do Maranhão (NIB/UFMA), especificamente no que se refere à constituição do acervodas bibliotecas que o compõe, no período da

\footnotetext{
${ }^{1}$ Professora Dr. a do Departamento de Biblioteconomia da Universidade Federal do Maranhão.

${ }^{2}$ Bacharel em Biblioteconomia pela Universidade Federal do Maranhão. Rua do Sol, 213 -Centro, Santa Inês, Maranhão, Brasil. Cel.: (98) 98128-3055. E-mail: gm.alessandra@hotmail.com
} 


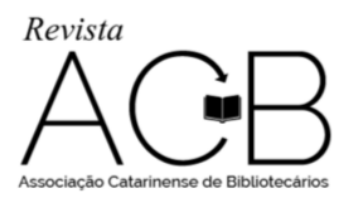

O uso de relatórios anuais de atividades como instrumento de avaliação do acervo das bibliotecas que compõem o Núcleo Integrado de Bibliotecas a Universidade Federal do Maranhão no período de 2008 a 2012 - Cláudia Maria Pinho de Abreu Pecegueiro e Alessandra Gomes Melo Aguiar Freitas

implementação do Programa de Apoio a Planos de Reestruturação e Expansão das Universidades Federais (Reuni), que compreende os anos de 2008 a 2012.A escolha por este período de tempo justifica-se pela necessidade de perceber as mudanças ocorridas no acervo do NIB/UFMA através da análise dos relatórios, a partir da adoção do Reuni, desde a sua instituição, visto que o programa preconiza a expansão universitária e, o que se espera, é que a biblioteca acompanhe esse crescimento.

A análise dos relatórios Anuais como instrumentos de avaliação do acervo das bibliotecas que compõem o NIB/UFMA justifica-se também por este ser um instrumento que representa a realidade da biblioteca, capaz de mostrar ao Bibliotecário dados que possam identificar falhas e/ou acertos no que se refere ao Planejamento, o que pode ser essencial para um melhor desempenho no processo deavaliação pelo Sistema Nacional de avaliação da Educação Superior (SINAES), programa instituído pelo Governo Federal, que estabelece, entre outros critérios, o número mínimo de títulos a serem adquiridos por cada curso que a Universidade acolhe. Assim, se a Universidade cresce devido as medidas do Reuni, o número de alunos também cresce, e o número de livros também deve crescer para que a biblioteca esteja de acordo com os critérios estabelecidos pelo SINAES; e uma forma de mensurar se esses objetivos estão sendo alcançados, é através da Análise dos relatórios Anuais de Atividades de uma Unidade Informacional.

É conveniente ressaltar que os relatórios de forma geral são instrumentos que contém dados sobre o real contexto em que biblioteca se encontra, portanto, esta ferramenta é de fundamental importância no processo de avaliação e Planejamento da biblioteca Universitária e, de certa forma, no Planejamento da própria Universidade a qual faz parte, uma vez que a B.U subsidia as atividades de ensino, pesquisa e extensão, cerne da existência das Universidades. No que se refere à UFMA, os relatórios anuais de atividades do seu Núcleo Integrado de bibliotecas podem servir de material essencial para a construção do Plano de Desenvolvimento Institucional da Universidade nos eixos em que o Núcleo está inserido.

A construção teórica deste estudo aborda aspectos da Administração de bibliotecas, especialmente no que tange a elaboração e uso dos relatórios de gestão, e conceitos sobre Planejamento e avaliação, apontando para a interpretação correta da realidade em que o NIB/UFMA está inserido. A pesquisa foi realizada a partir de dois contextos: o Núcleo Integrado de bibliotecas (NIB), e a Universidade Federal do Maranhão, entidade a qual o NIB é vinculado. Para isto, foram realizadas pesquisas em nível bibliográfico e documental que resultaram em dados qualitativos referentes a análises às bibliografias consultadas, e aos documentos de gestão do Núcleo Integrado de bibliotecas da Universidade Federal do Maranhão $\mathrm{O}$ conhecimento teórico e a análise prática possibilitou uma melhor visualização dos dados sobre o acervodo Núcleo em questão.

Assim, entre outros aspectos, este estudo pretende contribuir com um referencial teórico que auxilie na compreensão do processo de gestão de bibliotecas Universitárias através da abordagem dos conceitos de Planejamento, avaliação e sobre osrelatórios de gestão, a ser difundido entre os Bibliotecários, acreditando que este profissional, ao gerenciar a organização, possa colaborar para as mudanças necessárias no contexto organizacional ao qual pertence.

\section{PLANEJAMENTO: conceitos e considerações}

A elaboração de relatórios faz parte de um processo cíclico onde participam também os processos de Planejamento e a avaliação. Entende-se que, por ser um ciclo, não existe uma ordem estabelecida, não tendo obrigatoriamente um começo ou fim. Porém, neste estudo, o Planejamento será abordado como a primeira atividade a ser realizada rumo a elaboração de relatórios.

As atividades de Planejamento e avaliação servem de base no processo de construção dos relatórios ao fornecer um parâmetro de análise das atividades (pelo Planejamento) e pela mensuração do que foi realizado no contexto da Unidade Informacional (através da avaliação), gerando dados suficientes para a elaboração de relatórios, documentos que trazem informações sobre a realidade de cada um dos diversos aspectos que compõe a biblioteca, sejam eles o espaço físico, o setor de Referência, de processamento 


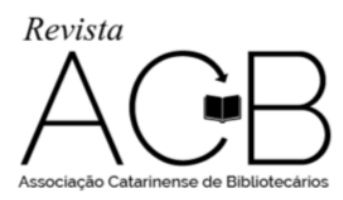

O uso de relatórios anuais de atividades como instrumento de avaliação do acervo das bibliotecas que compõem o Núcleo Integrado de Bibliotecas a Universidade Federal do Maranhão no período de 2008 a 2012 - Cláudia Maria Pinho de Abreu Pecegueiro e Alessandra Gomes Melo Aguiar Freitas

técnico, do acervo, etc. Assim sendo, recorre-se à teoria referente ao Planejamento para que se possa entrar no contexto desta pesquisa.

Encontra-se um emaranhado de ideias sobre o Planejamento que convergem para um ponto em comum: a mensuração antecipada de medidas que possam interferir positivamente ou negativamente no fluxo de atividades de uma organização a partir do conhecimento da realidade da mesma.

Nesta perspectiva, o conceito de Planejamento, através da percepção de Chiavenato (2008, p.342), nos mostra que

[...] o planejamento constitui hoje uma responsabilidade essencial em qualquer tipo de organização ou de atividade. O planejamento constitui a função inicial da administração. Antes que qualquer função administrativa seja executada, a administração precisa planejar, ou seja, determinar os objetivos e os meios necessários para alcançá-los adequadamente.

Isto significa dizer que este processo se constitui principalmente da atitude de tentar reduzir as incertezas da organização, se os objetivos elaborados propiciarem meios e ações específicos para o alcance dos resultados pré-estabelecidos.

O Planejamento pode ser considerado uma das principais ferramentas administrativas por ser o instrumento que melhor permite determinar ações que ajudem no alcance de um foco organizacional; é, portanto, um instrumento fundamental para o gestor construir objetivos, estabelecer metas e manter o foco da organização.

Os autores Almeida (2005) e Valentim (2013) discutem quanto aos conceitos do Planejamento analisando-os através dos tipos a que este se apresenta, podendo ser definidos da seguinte forma:

a) planejamento estratégico: realizado pela direção geral (alta administração), estabelece as diretrizes para a organização; abrange a organização como um todo, afeta-a a longo prazo e está voltado às relações entre a organização e o ambiente e sujeito a incertezas provocadas por esse ambiente;

b) planejamento tático ou intermediário: realizado pelos executivos de diretoria e gerenciais (nível médio), é o desdobramento do Planejamento estratégico. Serve para gerenciar recursos visando atingir os níveis estratégicos (projetos, ações, etc). Relaciona-se em geral a atividades presentes e de futuro próximo e sua função é controlar e integrar as operações nas organizações;

c) planejamento operacional: realizado pelos chefes de departamento (menor nível), decide "o que fazer" e "como fazer". Objetiva otimizar as operações elaboração de procedimentos, visando a realização dos planos estratégicos e táticos. Tem caráter imediatista, caracterizando-se por ser de curto prazo e de abrangência local.

O Planejamento estratégico se situa no topo da pirâmide, a fim de determinar responsabilidades na construção do Planejamento, que trata da construção da identidade da organização ao ser responsável pelo estabelecimento da visão, missão, valores e objetivos da organização, sendo válido para toda organização; o nível de Planejamento tático, considerado um nível intermediário por estar entre os níveis estratégico e operacional, tem o papel de pôr em prática os planos elaborados pelo nível estratégico dentro dos departamentos da organização, desdobrando os objetivos institucionais de forma a auxiliar na consecução dos seus objetivos; e o Planejamento operacional, o menor nível do Planejamento, é responsável por colocar em prática os planos elaborados pelo nível tático, envolvendo cada tarefa e meta da organização.

É possível perceber que não há exatamente um alto grau de diferenciação entre os níveis do Planejamento, o que ocorre na verdade é uma complementação. Os três tipos de Planejamento formam um processo contínuo e integrado.

O Planejamento sugere uma série de atividades que podem servir de normas convencionadas pelas instâncias competentes das organizações, permitindo um fluxo ordenado de ações e resultados. Tal ferramenta torna-se importante à medida que utiliza da melhor forma possível o conhecimento gerado a partir das características da própria organização, como os recursos existentes (espaço físico, mobiliário, estrutura organizacional, recursos humanos, acervo, processamento técnico, usuários etc), suas 


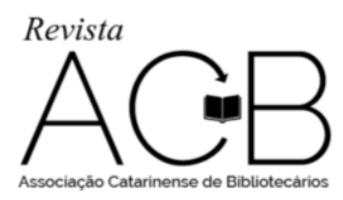

O uso de relatórios anuais de atividades como instrumento de avaliação do acervo das bibliotecas que compõem o Núcleo Integrado de Bibliotecas a Universidade Federal do Maranhão no período de 2008 a 2012 - Cláudia Maria Pinho de Abreu Pecegueiro e Alessandra Gomes Melo Aguiar Freitas

oportunidades e ameaças (análise do ambiente externo), bem como seus pontos fortes e suas fraquezas (análise do ambiente interno), racionalizando o uso do seu patrimônio, podendo afetar diretamente o desempenho da instituição.

O mercado competitivo é o que impulsiona as organizações, e, como não pode ser diferente, as Instituições de Ensino Superior (IES), na busca do contínuo desenvolvimento através do aperfeiçoamento dos seus processos e políticas, fortalecem a gestão através de ações Planejadoras, resultando em medidas e atividades que possibilitam melhorias de curto, médio e longo prazo na execução de suas ações.

No que tange ao Planejamento no âmbito das IES, destaca-se o papel do Plano de Desenvolvimento Institucional (PDI), documento orientador no processo de tomadas de decisões, bem como norteador do caminho a ser percorrido pela instituição para o alcance de sua visão e missão institucionais. De acordo com o Instituto Federal de Roraima (2014, não paginado), o PDI “[...] serve para orientar o Planejamento da instituição no período de sua abrangência, identificando as ações e atividades a serem desenvolvidas tanto no âmbito acadêmico quanto administrativo.". O PDI é composto de informações sobre a visão, missão e objetivos da instituição e seus setores, bem como descreve o funcionamento de cada departamento que a compõe, apontando para dados da sua realidade e traçando metas para o futuro.

Desta forma, é correto afirmar que o Planejamento, tanto no contexto das Universidades, como em outras instituições, se torna completo quando é possibilitada a visão do todo, necessitando primeiramente a análise das partes que constituem o universo de cada organização; o PDI é um exemplo desta afirmativa.

Para os fins desse estudo, o Planejamento e seus processos são tratados no contexto da biblioteca Universitária, o que torna essencial a abrangência da pesquisa, uma vez que a B.U deve ser um dos principais meios de acesso a informação na Universidade.

\subsection{Planejamento em Unidades de Informação}

Mesmo com os seus métodos e princípios próprios, a prática da Biblioteconomia, assim como outras ciências, precisa se apoiar em outras áreas do conhecimento para que possa cumprir com seus propósitos. Quando feita através da Gestão de bibliotecas, a Biblioteconomia encontra como base para orientações os conhecimentos originados na Administração, para que possa auxiliar na superação dos desafios que são apresentados durante o exercício da função do Bibliotecário-Gestor. Desta forma, passase a considerar a biblioteca não só como o espaço de produção e disponibilização do conhecimento, mas também como um ambiente administrativamente bem estruturado com funções e atividades bem definidas, para seu eficaz funcionamento.

Deste modo, a biblioteca como organização ou empresa é um sistema que depende de vários setores para manter o seu funcionamento, tendo como principal objetivo atender as necessidades informacionais de uma comunidade. Para isso, é importante considerar o Planejamento como instrumento facilitador para o desenvolvimento de atividades dentro das Unidades Informacionais, conforme explica Lima (1996, p. 9):

O planejamento [...], por isso torna-se fundamental na medida em que o mesmo favorece a discussão da missão, dos objetivos, das políticas, das estratégias e dos mecanismos de controle e avaliação. A utilização do plano [...] é importante para as bibliotecas, mesmo com as restrições que se pode observar, pelo fato do mesmo estabelecer os elos de ligação entre os meios e os fins.

As bibliotecas possuem metas que devem ser alcançadas em congruência aos objetivos das organizações às quais pertencem e, desta forma, o Planejamento em Unidades de Informação surge como ferramenta para auxiliar na consecução destes objetivos, na medida em que este instrumento é o que propicia ao gestor bases para a construção e solidificação dos propósitos, objetivos e políticas gerais da organização.

Assim, de forma a complementar a elaboração do Planejamento em uma biblioteca Universitária, esta deve ainda "[...] integrar-se no planejamento e funcionamento global da Universidade e para isso 
O uso de relatórios anuais de atividades como instrumento de avaliação do acervo das bibliotecas que compõem o Núcleo Integrado de Bibliotecas a Universidade Federal do Maranhão no período de 2008 a 2012 - Cláudia Maria Pinho de Abreu Pecegueiro e Alessandra Gomes Melo Aguiar Freitas

deverá situar-se em nível hierárquico de suficiente autonomia e participação nas fases de decisão da política universitária." (LEMOS; MACEDO, 1974).

Deste modo,

[...] se por um lado ela reflete a natureza da organização, por outro ela induz à definição de objetivos a alcançar, a partir de um modelo de estrutura e de gestão, além de requerer a avaliaçãono sentido de medida do desempenho organizacional. (LUBISCO, 2011, p. 44).

Nesse sentido, entendendo o Planejamento como um guia que determina quais ações realizar para que os objetivos estabelecidos possam ser alcançados, entende-se também que, sem os parâmetros estabelecidos pelo Planejamento, não existirá um consenso sobre o que deve ser realizado dentro das organizações, o que pode ocasionar na ineficiência de serviços e produtos oferecidos pela organização, no caso, a biblioteca Universitária.

Para Walters (1993 apud BARBALHO; BERAQUET, 1995, p. 26), as principais perguntas a se fazer na elaboração de um Planejamento em Unidades Informacionais são:
a) Quem é a Unidade de Informação?
b) Para onde a Unidade de Informação deseja ir?
c) O que a Unidade de Informação quer ser e por quê?
d) O que a Unidade de Informação está fazendo para chegar lá?

As ações de Planejamento e avaliaçãodevem resultar na elaboração e análise de relatórios de gestãoo que levam ao compromisso com a construção de um novo Planejamento, tornando-se uma atividade cíclica. Esses aspectos são importantes na solidificação da identidade da Unidade de Informação à medida que se tornam instrumentos de orientação ao estabelecer um foco, servindo como norteadores adequados à consecução das metas organizacionais.

Entendendo o desenvolvimento de coleções como uma atividade de Planejamento, esta deve resultar em um plano detalhado que defina a sua rota de atuação, respeitando cada tipologia de biblioteca para que se possa responder a critérios específicos no desenvolvimento de suas Coleções.

No que se refere às bibliotecas Universitárias, encontra-se uma fala de Vergueiro (1989, p. 20-21) que esclarece sobre o desenvolvimento de coleções nesta tipologia de biblioteca:

[...] devem atender aos objetivos da Universidade, a saber, a pesquisa, o ensino e a extensão. Isto vai exigir, quase que necessariamente, uma coleção com forte tendência ao crescimento, pois atividades de pesquisa exigem uma grande gama de materiais para que o pesquisador possa ter acesso a todos os pontos de vista importantes ou necessários.

O resultado do desenvolvimento do acervo de uma biblioteca Universitária não atinge somente o órgão biblioteca, mas a Universidade como um todo, e, no Brasil, devido as exigências do Ministério da Educação (MEC), a biblioteca Universitária representa um setor de suma importância para o funcionamento das Universidades, pois a avaliação de seu acervoatravés do Sistema Nacional de avaliação da Educação Superior (SINAES) é utilizada para a validação e renovação de reconhecimento dos cursos de graduação.

Dessa forma, para um melhor esclarecimento sobre a atividade de avaliação, principalmente no que se refere à avaliação em bibliotecas Universitárias, segue-se explicitando sobre os seus principais conceitos e aplicações.

3BIBLIOTECAS UNIVERSITÁRIAS: avaliação de atividades

Tendo em vista que o conceito de avaliação é abrangente e que pode ser inserido em diversos segmentos, foca-se, nesta seção, o esclarecimento sobre os conceitos de avaliação voltados para o âmbito das bibliotecas Universitárias.

Avaliação implica necessariamente na construção de um desenho de mudança como "uma força positiva" (ALMEIDA, 2005). O seu foco se encontra na efetividade e na flexibilidade dos processos, promovendo melhor desempenho de resultados e processosna administração da empresa. A avaliação surge como uma necessidade de manter um sistema contínuo em prol da melhoria e sustentação da qualidade desejada pela organização. A falta de avaliação ocasiona prejuízos para a organização e o 


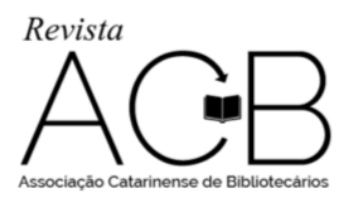

O uso de relatórios anuais de atividades como instrumento de avaliação do acervo das bibliotecas que compõem o Núcleo Integrado de Bibliotecas a Universidade Federal do Maranhão no período de 2008 a 2012 - Cláudia Maria Pinho de Abreu Pecegueiro e Alessandra Gomes Melo Aguiar Freitas

público, criando um clima organizacional desfavorável, o que acarreta uma queda de performance na empresa e até tomadas de decisões inconsequentes.

Em um contexto de crescimento da produção científica e tecnológica voltada para um mercado globalizado, as bibliotecas podem encontrar muitos obstáculos que as impeçam de responder às necessidades de uma clientela em constante mudança. Desse modo, o modelo de gestão do sistema de bibliotecas deve se basear em um plano estratégico de trabalho, com objetivos e metas estabelecidas.

Os serviços oferecidos por uma biblioteca, quando analisados de uma forma geral, são definidos a partir de dois eixos: primeiro pela sociedade como um todo, representada pelos usuários reais e potenciais que buscam a biblioteca como canal difusor de cultura, conhecimento e informação, característica pela qual ela pode ser validada objetivamente como uma organização social; e, segundo, pela base a que ela está erguida, a qual lhe imputam sua tipologia, sua missão, visão e valores, e o que ela produz. A relação que estabelece com a sociedade e com a instituição vinculada determinará os objetivos básicos da Unidade Informacional, ao implementar atividades e gerir os recursos destinados à satisfação dos usuários. Neste sentido, para que a prestação de serviços informacionais possa ser ampliada, melhorada, e tenha eficiência e maior controle, é preciso que a execução dessas atividades (ações e recursos), dentro do contexto da biblioteca sejam avaliadas, a fim de que os critérios definidos pelo Planejamento possam, de fato, ser executados.

Avaliação é a atividade cuja finalidade é “ [...] reunir dados úteis para a solução de problemas e tomada de decisões." (LANCASTER, 2004, p. 1). É uma atividade de diagnóstico e compõe etapa fundamental do Planejamento Bibliotecário, pois permite o conhecimento detalhado da atual situação com seus pontos fortes e pontos fracos, bem como oferecer subsídios para a formulação de soluções.

De forma geral, pensar em avaliação é ser analítico; é ser sujeito ativo para propiciar a transformação da ação conforme a sua realidade. No contexto administrativo, quando se exclui a avaliação dos seus processos, inclui-se a falta de dinamização, a desorganização e a ineficiência do sistema como um todo. De acordo com Lancaster $(2004$, p.8) "[...] uma avaliação é feita não como um exercício intelectual, mas para reunir dados úteis para atividades destinadas a solucionar problemas ou tomar decisões. ". Os resultados das Avaliações devem ser reunidos para que se elabore uma lista de prioridades. É importante entender que o desafio da mudança é uma oportunidade para a renovação das bibliotecas Universitárias e, consequentemente, do ensino superior brasileiro.

A avaliação é utilizada, de certa forma, como uma ação que busca medir os erros e acertos dentro da organização para identificar o nível de qualidade dos serviços oferecidos. Assim, por ser uma atividade de "fiscalização" das atividades realizadas, a avaliação serve também como instrumento de orientação entre o Planejamento e a ação.

O processo avaliativo possibilita diagnosticar questões relevantes ao funcionamento da Unidade Informacional, por isso, este se torna imprescindível no processo do Planejamento, uma vez que através da avaliação é gerado um conhecimento sobre a realidade do contexto em questão que servirá de base para a elaboração de novos planos de ação. A avaliação permite que o Planejamento seja continuamente aprimorado.

Voltando ao serviço de avaliação para o âmbito das bibliotecas Universitárias, convém indagar sobre qual a necessidade deste serviço para este tipo de organização. Pode-se dizer que o principal fator é o aspecto que implica na melhoria contínua da organização, e, segundo Lubisco (2011, p. 13)

[...] constitui-se em etapa posterior à execução do planejamento, atuando como meio de comparar os resultados alcançados com as metas estabelecidas e fornecendo elementos para as ações corretivas, quando necessárias, ou para a manutenção do padrão obtido.

Essa atuação deve revestir-se do amplo conhecimento sobre a organização, em todos os seus aspectos, não somente entre os segmentos que possam ser submetidos a intervenção, de forma a considerar a organização como um sistema onde as partes interagem entre si e com a comunidade a qual serve. 


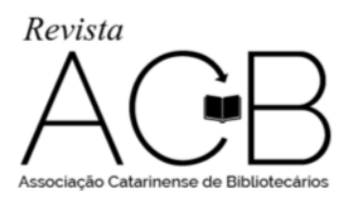

O uso de relatórios anuais de atividades como instrumento de avaliação do acervo das bibliotecas que compõem o Núcleo Integrado de Bibliotecas a Universidade Federal do Maranhão no período de 2008 a 2012 - Cláudia Maria Pinho de Abreu Pecegueiro e Alessandra Gomes Melo Aguiar Freitas

A atividade de avaliação deve surgir a partir de uma questão que exige respostas precisas: para que avaliar? (ALMEIDA, 2005), assim, o serviço de avaliação, por sua característica estratégica deve ser definido através da análise e reflexão dos fatos, sendo uma forma de aprendizagem cuja finalidade é aprimorar o conjunto de atividades e dos meios operacionais que possibilitem não apenas concertar os erros cometidos, mas também e, principalmente, evitá-los.

No que tange àavaliação de bibliotecas Universitárias no Brasil, destacam-se os esforços direcionados à avaliação de bibliotecas Universitárias no âmbito do Sistema Nacional de avaliação da Educação Superior (SINAES).

O objetivo do SINAES, conforme referido, é avaliar as instituições, os cursos e o desempenho dos estudantes de nível superior, analisando os aspectos que compõem a tríade a qual as Universidades estão baseadas: o ensino, a pesquisa e a extensão, levando em consideração também a responsabilidade social, o desempenho dos alunos, a gestão da instituição, o corpo docente, as instalações, entre outros pontos.

A avaliação do SINAES é coordenada e supervisionada pela Comissão Nacional de avaliação da Educação Superior (CONAES), e sua operacionalização é de responsabilidade do Instituto Nacional de Estudos e Pesquisas Educacionais Anísio Teixeira (INEP). Os dados obtidos através do SINAES são utilizados pelas IES, para orientação da eficiência institucional e eficácia acadêmica e social; pelos órgãos governamentais para orientar políticas públicas e pelos estudantes, instituições acadêmicas e público em geral, para orientar suas decisões quanto à realidade dos cursos e das instituições.

Desta forma, o resultado da avaliação do SINAES

[...] fornece elementos para que os verificadores elaborem uma opinião sobre as potencialidades da instituição para credenciar-se como instituição capaz de ministrar educação superior presencial ou à distância, e para implantar os cursos superiores que pretende oferecer. É o momento também de verificar se a infra-estrutura (ambientes, equipamentos e outros recursos físicos e acadêmicos apropriados) e se o pessoal docente e técnico estão de fato em condições de serem colocados a serviço dos objetivos maiores da IES [...] além de tentar estabelecer comparações entre as situações reais verificadas, as intenções declaradas e os documentos institucionais previamente examinados. O instrumento de verificação é constituído de quatro dimensões: contexto institucional, organização didático-pedagógica, corpo docente e instalações. Cada uma destas dimensões desdobra-se em diversas categorias de análise. Na dimensão contexto institucional são analisadas as características da instituição, administração, políticas e programas de incentivos e benefícios. $\mathrm{Na}$ dimensão organização didático-pedagógica, são analisadas a administração acadêmica e o projeto do(s) curso(s) e sua adequação às diretrizes curriculares e aos padrões de qualidade. Na dimensão corpo docente, são analisadas a formação acadêmica e profissional e as condições de trabalho. Na dimensão das Instalações, são analisadas as instalações gerais, biblioteca, instalações, condições materiais e laboratórios específicos para, no mínimo, atender ao primeiro ano de funcionamento do(s) curso(s) proposto(s), condições de acessibilidade para portadores de necessidades especiais. Cada uma das categorias de análise, por sua vez, desdobra-se em diversos indicadores.(INEP, 2004, p. 36).

Nos últimos quinze anos do século XXI, verifica-se os empenhos voltados para a ampliação do Ensino Superior no Brasil. Neste sentido, foram criadas e implementadas várias Políticas Públicas voltadas para este propósito como, por exemplo: o Programa Universidade para todos (PROUNI), o Financiamento ao Estudante de Ensino Superior (FIES), a Universidade Aberta do Brasil (UAB) e o Programa de apoio ao Plano de Reestruturação e Expansão das Universidades Federais (Reuni).

A implantação do Reuni, especificamente, teve como objetivo a ampliação dos meios e dos serviços oferecidos pelas Instituições de Ensino Superior, isso quer dizer que, o governo federal deve fornecer subsídios suficientes para a ampliação do acesso e a permanência dos alunos no ensino superior.

Entre as principais metas do Reuni destacam-se a ampliação das vagas de graduação oferecidas pelas IES; a permanência dos alunos nos cursos de graduação, visando ao aumento do número de alunos que concluem o curso, entre outras.

Concomitantemente aos objetivos da chamada Reforma Universitária, o SINAES, sistema que já vinha sendo utilizado pelo MEC, tornou-se essencial para assegurar se as expansões alcançadas estão de 


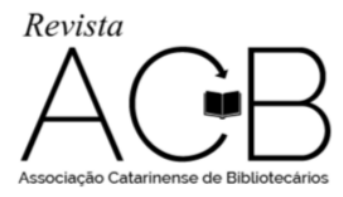

O uso de relatórios anuais de atividades como instrumento de avaliação do acervo das bibliotecas que compõem o Núcleo Integrado de Bibliotecas a Universidade Federal do Maranhão no período de 2008 a 2012 - Cláudia Maria Pinho de Abreu Pecegueiro e Alessandra Gomes Melo Aguiar Freitas

acordo com os padrões almejados para a Educação Superior, desta forma, entende-se neste estudo que a partir da implementação do Reuni, as informações obtidas pelo SINAES passam a ser um instrumentocomplementarà sua execução de forma a garantir a qualidade dos objetivos do Programa de Apoio a Planos de Reestruturação e Expansão das Universidades Federais, visto que, se o objetivo do Reuni está voltado para a ampliação e expansão do ensino superior, em número de cursos oferecidos e em número de alunos matriculados e graduados, o SINAES surge como uma ferramenta de fiscalização e controle da qualidade da expansão universitária, servindo como referencial para a adequação das Universidades nesse processo de expansão.

De acordo com Barcelos e Gomes (2004), na atribuição dos conceitos avaliativos (de nível 1 a 5), a avaliação da biblioteca é responsável por $40 \%$ da nota. Os indicadores a serem avaliados na biblioteca são: espaço físico, acervo e serviços. No que se refere ao acervo, o instrumento do SINAES destaca que o referencial mínimo para o seu desenvolvimento é de 3 títulos de Bibliografia Básica, sendo estabelecidos critérios de análise como se pode observar no quadro 2 :

Quadro 1 - Relação de conceitos atribuídos à quantidade de títulos no acervo:

\begin{tabular}{|c|c|c|}
\hline INDICADOR & CONCEITO & CRITÉRIO DE ANÁLISE \\
\hline \multirow{5}{*}{$\begin{array}{c}\text { Bibliografia } \\
\text { Básica }\end{array}$} & 1 & $\begin{array}{l}\text { Quando o acervo da bibliografia básica não está disponível; ou quando está } \\
\text { disponível na proporção média de um exemplar para } \mathbf{2 0} \text { ou mais vagas } \\
\text { anuais pretendidas/autorizadas, de cada uma das unidades curriculares, de } \\
\text { todos os cursos que efetivamente utilizam o acervo; ou quando o acervo } \\
\text { existente não está informatizado e tombado junto ao patrimônio da IES; ou } \\
\text { quando não existe um mínimo de três títulos por unidade curricular. }\end{array}$ \\
\hline & 2 & $\begin{array}{l}\text { Quando o acervo da bibliografia básica, com no mínimo três títulos por } \\
\text { unidade curricular, está disponível na proporção média de um exemplar para } \\
\text { a faixa de } \mathbf{1 5} \text { a menos de } \mathbf{2 0} \text { vagas anuais pretendidas/autorizadas, de cada } \\
\text { uma das unidades curriculares, de todos os cursos que efetivamente utilizam } \\
\text { o acervo, além de estar informatizado e tombado junto ao patrimônio da } \\
\text { IES. }\end{array}$ \\
\hline & 3 & $\begin{array}{l}\text { Quando o acervo da bibliografia básica, com no mínimo três títulos por } \\
\text { unidade curricular, está disponível na proporção média de um exemplar para } \\
\text { a faixa de } \mathbf{1 0} \text { a menos de } \mathbf{1 5} \text { vagas anuais pretendidas/autorizadas, de cada } \\
\text { uma das unidades curriculares, de todos os cursos que efetivamente utilizam } \\
\text { o acervo, além de estar informatizado e tombado junto ao patrimônio da } \\
\text { IES. }\end{array}$ \\
\hline & 4 & $\begin{array}{l}\text { Quando o acervo da bibliografia básica, com no mínimo três títulos por } \\
\text { unidade curricular, está disponível na proporção média de um exemplar para } \\
\text { a faixa de } \mathbf{5} \text { a menos de } \mathbf{1 0} \text { vagas anuais pretendidas/autorizadas, de cada } \\
\text { uma das unidades curriculares, de todos os cursos que efetivamente utilizam } \\
\text { o acervo, além de estar informatizado e tombado junto ao patrimônio da } \\
\text { IES. }\end{array}$ \\
\hline & 5 & $\begin{array}{l}\text { Quando o acervo da bibliografia básica, com no mínimo três títulos por } \\
\text { unidade curricular, está disponível na proporção média de um exemplar } \\
\text { para menos de } 5 \text { vagas anuais pretendidas/autorizadas, de cada uma das } \\
\text { unidades curriculares, de todos os cursos que efetivamente utilizam o } \\
\text { acervo, além de estar informatizado e tombado junto ao patrimônio da IES. }\end{array}$ \\
\hline
\end{tabular}

Fonte: Brasil (2012, não paginado).

Para uma melhor visualização da aplicação destes conceitos, utilizando como referência o curso de Biblioteconomia da Universidade Federal do Maranhão que oferece 92 vagas anualmente, e com uma 
O uso de relatórios anuais de atividades como instrumento de avaliação do acervo das bibliotecas que compõem o Núcleo Integrado de Bibliotecas a Universidade Federal do Maranhão no período de 2008 a 2012 - Cláudia Maria Pinho de Abreu Pecegueiro e Alessandra Gomes Melo Aguiar Freitas

carga horária mínima de 2.910 horas, distribuídas em 44 unidades curriculares, deve possuir, na bibliografia básica, um mínimo de três títulos por unidade curricular, o que totaliza 132 títulos. No que se refere a distribuição por alunos estes devem ser na proporção média de um exemplar para a faixa de 15 a 20 vagas anuais. Quando divide-se a entrada anual de 92 alunos por 15 exemplares tem-se como valor de referência 7 exemplares de cada título por aluno.

De forma concreta e conforme o instrumento de avaliação dos cursos de graduação presencial e à distância, no que se refere a bibliografia básica,no item 3.6 (INEP, 2015, p. 30), há possibilitado a IES a oferta de livros eletrônicos, o que não é, ainda, uma realidade na UFMA.

Observa-se, portanto, que a avaliação do SINAES nas bibliotecas Universitárias trata-se de uma avaliação de caráter quantitativo que, segundo Rothen (2006), tem um enfoque quantitativo e centralizado pelo Estado, por utilizar instrumentos de avaliação com indicadores numéricos e pré-elaborados pelo Instituto Nacional de Estudos e Pesquisas Educacionais Anísio Teixeira (INEP).

A partir deste ponto, evidencia-se a pluralidade dos serviços oferecidos por uma Unidade Informacional e o princípio da integração sistêmica da biblioteca, onde os aspectos a serem avaliados são interdependentes. Contudo, a avaliação pode ser realizada sobre aspectos determinados que, para os objetivos deste estudo, estará voltado para a avaliação do desenvolvimento do acervodas bibliotecas que compõem o NIB/UFMA, a partir da implementação do Reuni, utilizando a análise dos relatórios Anuais de atividades do NIB no período de 2008 a 2012.

\subsection{Relatórios de Gestão como fontes de Informação}

Considerando toda a complexidade envolvida no processo de avaliação e assim a necessidade de deter mecanismos que tornem esse processo válido, destaca-se o relatório como um instrumento de gestão e auxílio nesse processo de avaliação, responsável por relatar, comunicar e evidenciar as práticas adotadas pela instituição avaliada. O relatório apresenta os resultados alcançados, identificando se as metas foram cumpridas ou não, registra os avanços, as dificuldades encontradas e as medidas que foram ou deverão ser tomadas.

A Associação Brasileira de Normas Técnicas (ABNT) possui em seu corpo normativo a NBR 10719 que se refere à apresentação de um relatório técnico científico e possui versões que datam de 1989, 2011 e 2015. Para a complementação do entendimento deste estudo, utilizou-se o conceito que consta na norma do ano de 1989, por se tratar de um entendimento ainda atual, onde caracteriza o relatório como um

\footnotetext{
Documento que relata formalmente os resultados ou progressos obtidos em investigação de pesquisa e desenvolvimento ou que descreve a situação de uma questão técnica ou científica. $\mathrm{O}$ relatório técnico científico apresenta sistematicamente informação suficiente para que um leitor qualificado trace conclusões e faça recomendações. É estabelecido em função e sob a responsabilidade de um organismo ou pessoa a quem será submetido [...]. (ABNT, 1989, p. 2).
}

O relatório constitui-se como um instrumento fundamental para o acompanhamento, controle e avaliação das ações, serviços e funcionamento da instituição. No âmbito das bibliotecas o relatório é utilizado como um instrumento que especifica o "[...] conjunto de informações sobre acervo, serviços prestados, usuários e recursos humanos, físicos, materiais e financeiros ordenados de modo a mostrar a situação da biblioteca em dado período de tempo." (ALMEIDA, 2005, p.37). Normalmente, esse tipo de instrumento é produzido a partir de um plano de trabalho já estabelecido, sendo o seu referencial, para assim identificar se o que foi planejado está sendo executado.

Portanto, o relatório foi criado para ser um auxílio aos gestores no que diz respeito ao Planejamento podendo ser anuais, semestrais, trimestrais ou mensais. O que deverá ser avaliado e por consequência se fazer presente no relatório irá depender do aproveitamento que se pretende fazer com isso, assim como as múltiplas relações possíveis de serem estabelecidas entre os vários dados de uma biblioteca. A análise de um relatório permite uma maior possibilidade de compreensão dos problemas, ajudando na busca de suas 
O uso de relatórios anuais de atividades como instrumento de avaliação do acervo das bibliotecas que compõem o Núcleo Integrado de Bibliotecas a Universidade Federal do Maranhão no período de 2008 a 2012 - Cláudia Maria Pinho de Abreu Pecegueiro e Alessandra Gomes Melo Aguiar Freitas

soluções. O relatório deve seguir princípios e diretrizes que assegurem a exatidão e a confiabilidade das informações fornecidas, tendo como propósito, também, prestar conta quanto ao desempenho organizacional da instituição, no caso, a biblioteca.

Os relatórios de gestão têm por importância avaliar o desempenho da biblioteca, apoiar o gestor nas tomadas de decisão, possibilitar os meios para o aperfeiçoamento contínuo da gestão e das ações e serviços prestados, subsidiar o trabalho interno e externo da biblioteca, identificar os resultados e se os mesmos correspondem às metas pré-definidas. Assim,

É com base no conjunto de relatórios da biblioteca que a coordenação poderá definir metas para o sistema, elaborar e implantar projetos integrados que correspondem a suas necessidades reais, captar recursos de entidades financiadoras ou patrocinadoras e gerir, enfim, o sistema. (ALMEIDA, 2005, p. 39).

Entendendo o impacto demográfico causado pelo Reuni e considerando os aspectos definidos para o desenvolvimento do acervo pelo SINAES, acredita-se que as bibliotecas que compõem o NIB/UFMA devam acompanhar as mudanças ocorridas neste processo, respondendo as demandas resultantes da implementação destes planos.

\section{RESULTADOS E DISCUSSÃO}

Como já citado anteriormente no decorrer deste trabalho, para a realização deste estudo foram analisados os relatórios Anuais de atividades do Núcleo Integrado de bibliotecas da UFMA, voltando a pesquisa para o acervodas bibliotecas que compõe o Núcleo.

O NIB, foi criado no dia 2 de fevereiro de 2004 pela resolução no 73/2004 - CONSUN, possui 11 unidades ativas distribuídas no campus de São Luís, incluindo além da biblioteca Central, as bibliotecas: de Enfermagem, de Medicina, do LABOHIDRO e a do COLUN; a de Pós-Graduação em Ciências Exatas/Tecnologia, a de Pós-graduação em Ciências Sociais, e a de Pós-graduação em Saúde e Meio Ambiente, e outras bibliotecas nos campi do interior.

Os relatórios analisados foram elaborados pelo polo da biblioteca Central da UFMA por ser a principal unidade do NIB/UFMA e, por esta razão, a BC centraliza grande parte dosprocessos técnicos e administrativos, como a própria elaboração de relatórios e a participação nos processos de desenvolvimento de coleções. Desta forma, as informações contidas nos relatórios Anuais analisados representam o funcionamento de todas as bibliotecas que integram o Núcleo Integrado de bibliotecas da UFMA.

Além do quesito "acervo", o relatório apresenta campos como os descritos no quadro abaixo:

Quadro 2 - Aspectos abordados pelos relatórios Anuais de atividades do NIB

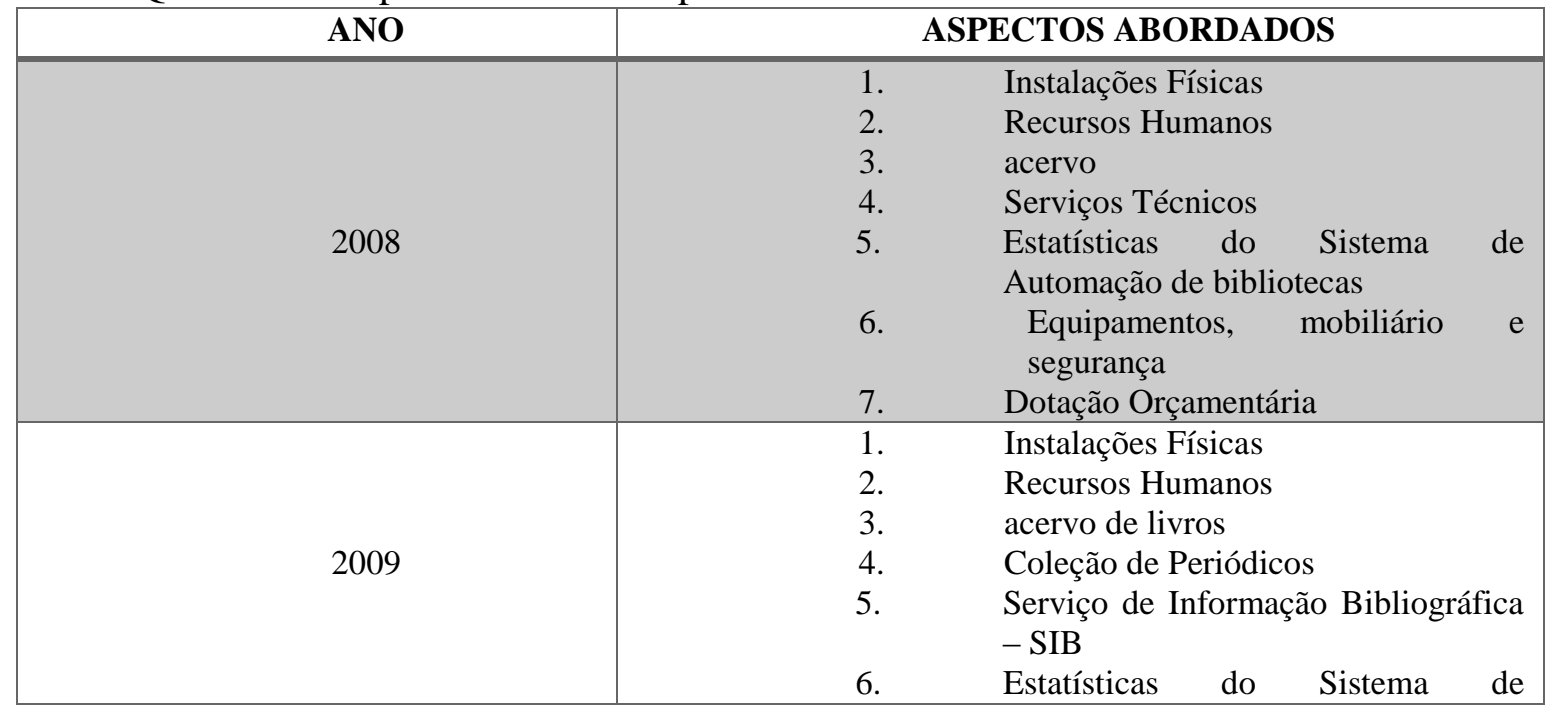




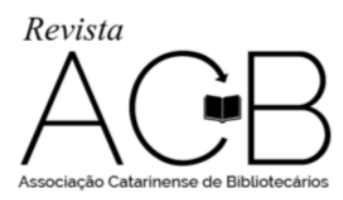

O uso de relatórios anuais de atividades como instrumento de avaliação do acervo das bibliotecas que compõem o Núcleo Integrado de Bibliotecas a Universidade Federal do Maranhão no período de 2008 a 2012 - Cláudia Maria Pinho de Abreu Pecegueiro e Alessandra Gomes Melo Aguiar Freitas

\begin{tabular}{|c|c|c|}
\hline & $\begin{array}{l}7 . \\
8 .\end{array}$ & $\begin{array}{l}\text { Automação de bibliotecas } \\
\text { Equipamento e Mobiliário } \\
\text { Recursos utilizados }\end{array}$ \\
\hline 2010 & $\begin{array}{l}2 . \\
3 . \\
4 . \\
5 .\end{array}$ & $\begin{array}{l}\text { Infraestrutura, equipamentos e } \\
\text { mobiliário } \\
\text { Recursos Humanos } \\
\text { Coleção de livros e periódicos } \\
\text { Serviço técnico e automação de } \\
\text { sistema } \\
\text { Recursos utilizados }\end{array}$ \\
\hline 2011 & $\begin{array}{r}1 . \\
2 . \\
3 . \\
4 . \\
\text { sistema } \\
5 .\end{array}$ & $\begin{array}{l}\text { Infraestrutura, equipamentos e } \\
\text { mobiliário } \\
\text { Recursos Humanos } \\
\text { Coleção de livros e periódicos } \\
\text { Serviço técnico e automação de } \\
\text { Recursos utilizados }\end{array}$ \\
\hline 2012 & $\begin{array}{l}1 . \\
2 . \\
3 . \\
4 . \\
5 .\end{array}$ & $\begin{array}{l}\text { Infraestrutura, equipamentos e } \\
\text { mobiliário } \\
\text { Recursos Humanos } \\
\text { Coleção de livros e periódicos } \\
\text { Serviço Técnico e automação de } \\
\text { sistema } \\
\text { Resumo dos recursos utilizados }\end{array}$ \\
\hline
\end{tabular}

Fonte: UFMA $(2008,2009,2010,2011,2012)$.

Estes foram os aspectos abordados nos relatórios Anuais de atividades do NIB no período de 2008 a 2012, o que nos leva especificamente, à análise dos dados referentes ao quesito acervo.

A partir da mensuração das informações contidas nos relatórios, elaborou-se uma ficha de análise para uma melhor visualização dos aspectos relevantes de cada ano, conforme segue:

Quadro 3 - Ficha de Análise de dados

\begin{tabular}{|c|c|c|c|c|}
\hline \multirow{3}{*}{ ANO } & \multicolumn{4}{|c|}{ FICHA DE ANÁLISE DE DADOS } \\
\hline & \multicolumn{4}{|c|}{ CRITÉRIO DE ANÁLISE } \\
\hline & \multicolumn{2}{|c|}{$\begin{array}{l}\text { AQUISIÇÃO DE LIVROS IMPRESSOS } \\
\text { (No DE TÍTULOS) }\end{array}$} & \multicolumn{2}{|c|}{$\begin{array}{c}\text { AQUISIÇÃO DE LIVROS ELETRÔNICOS } \\
\left(\mathbf{N}^{\circ} \text { DE TÍTULOS) }\right.\end{array}$} \\
\hline \multirow[t]{3}{*}{2008} & COMPRA & 17.664 títulos & \multirow{2}{*}{\multicolumn{2}{|c|}{ NÃO INFORMADO }} \\
\hline & DOAÇÃO & 4.799 títulos & & \\
\hline & TOTAL & 22.463 títulos & & \\
\hline \multirow[t]{3}{*}{2009} & COMPRA & 11.025 títulos & & \\
\hline & DOAÇÃO & 5.286 títulos & \multicolumn{2}{|c|}{ NÃO INFORMADO } \\
\hline & TOTAL & 16.311 títulos & & \\
\hline \multirow[t]{3}{*}{2010} & COMPRA & 10.308 títulos & \multirow{2}{*}{\multicolumn{2}{|c|}{ NÃO INFORMADO }} \\
\hline & DOAÇÃO & 2.858 títulos & & \\
\hline & TOTAL & 13.166 títulos & & \\
\hline \multirow{3}{*}{2011} & & & ACESSO PERPÉTUO & 3.400 títulos \\
\hline & \multirow{2}{*}{\multicolumn{2}{|c|}{ NÃO INFORMADO }} & ASSINATURA DE COLEÇÃO & 76.000 títulos \\
\hline & & & $\begin{array}{l}\text { TOTAL } \\
\end{array}$ & 79.400 títulos \\
\hline \multirow[t]{3}{*}{2012} & \multirow{3}{*}{\multicolumn{2}{|c|}{ NÃO INFORMADO }} & ACESSO PERPÉTUO & $\cong 1.212$ títulos \\
\hline & & & ASSINATURA DE COLEÇÃO & 77.000 títulos \\
\hline & & & \begin{tabular}{|l} 
TOTAL \\
\end{tabular} & $\cong 78.212$ títulos \\
\hline
\end{tabular}




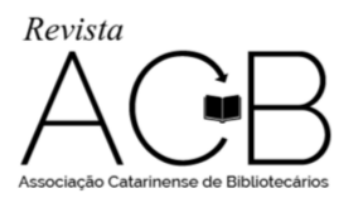

O uso de relatórios anuais de atividades como instrumento de avaliação do acervo das bibliotecas que compõem o Núcleo Integrado de Bibliotecas a Universidade Federal do Maranhão no período de 2008 a 2012 - Cláudia Maria Pinho de Abreu Pecegueiro e Alessandra Gomes Melo Aguiar Freitas

$\mathrm{O}$ acesso aosrelatórios analisados foi realizadoin loco, por estes não estarem retidos na base de dados do sistema gerencial do NIB. O sistema utilizado pelo Núcleo de Bibliotecas da Universidade Federal do Maranhão é o Sistema Integrado de Gestão de Atividades Acadêmicas (SIGAA) que não possui opções para o preenchimento de campos específicos relacionados aos aspectos analisados neste estudo.

Os relatórios verificadosapresentam vários pontos de vulnerabilidade, não permitindo a construção de conclusões pertinentes. Não há uma uniformidade na exposição dos dados nos relatórios no quesito "acervo", sendo que o texto contido nos instrumentos de 2008, 2009 e 2010 são quase idênticos, mudando apenas os dados quantitativos sobre os títulos adquiridos e algumas considerações rasas. Os relatórios de 2011 e 2012 apresentam aspectos completamente diferentes dos anos anteriores, e, quanto à aquisição, especificam apenas o valor financeiro despendido para a aquisição de livros de publicação nacional e estrangeira.

Tentou-se estabelecer, apesar das dificuldades encontradas, um padrão de crescimento do acervo, considerando, inclusive, a aquisição de livros eletrônicos entre os anos de 2008 e 2012. No intuito de representar visualmente as informações contidas nos relatórios, elaborou-se um gráfico onde constam de forma mais clara os números referentes ao crescimento do acervo, como pode ser observado a seguir:

\section{Gráfico 1 - Crescimento do acervo entre 2008-2012}

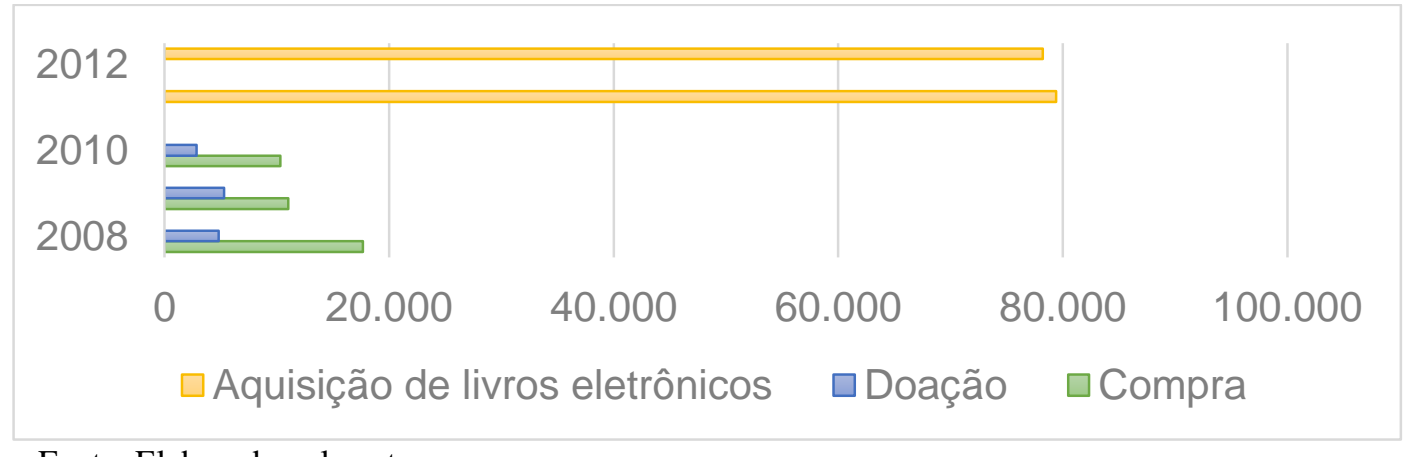

Fonte: Elaborado pela autora.

Os dados disponíveis nos relatórios analisados, leva a entender que houve uma diminuição na aquisição de livros durante os anos de 2008 a 2010, sendo subentendida a não existência de livros eletrônicos nestes anos, culminando com um boom de livros eletrônicos nos anos de 2011 e 2012. Observa-se também a não especificação do quantitativo de livros impressos adquiridos nos anos de 2011 e 2012, como pode ser observado no Gráfico 1.

Apesar da não existência de uma conformidade sobre os dados contidos nos relatórios, chega-se a conclusão de que os relatórios anuais do NIB/UFMA servem sim como instrumentos para avaliação do acervo, porém, devido a falta de dados suficientes, estes documentos pouco têm a contribuir na elaboração de novos Planejamentos no contexto do Núcleo. $\mathrm{Na}$ análise geral dos relatórios, surgem algumas lacunas a serem respondidas: Quais são as áreas de maior déficit do acervo nos anos analisados? Quais áreas foram beneficiadas em cada ano? Desde quando o NIB/UFMA adotou os livros eletrônicos (visto que estes só foram mencionados nos relatórios de 2011 e 2012)? Quais as bibliotecas beneficiadas pela aquisição de material em cada ano? Quanto, em relação a custos, foi despendido na aquisição de materiais bibliográficos para cada área e para cada biblioteca do NIB? E quanto, em relação a números, foram os materiais adquiridos nos anos em que só são apresentados valores financeiros? Entende-se que quando uma nova obra é inserida no acervo, esta passa por um processo técnico e é inclusa no sistema de gerenciamento da biblioteca, o que nos leva a acreditar que os dados inseridos nos relatórios analisados não foram consultados no sistema utilizado no Núcleo.

De acordo com Almeida (2005, p.17) 
O uso de relatórios anuais de atividades como instrumento de avaliação do acervo das bibliotecas que compõem o Núcleo Integrado de Bibliotecas a Universidade Federal do Maranhão no período de 2008 a 2012 - Cláudia Maria Pinho de Abreu Pecegueiro e Alessandra Gomes Melo Aguiar Freitas

A análise de relatórios de diferentes bibliotecas tem mostrado que as estatísticas nem sempre servem aos propósitos do planejamento, pois, em geral, não passam de simples contagem de ocorrências ou materiais, que não resultam de estudos racionais [...]. Números são importantes, mas devem fazer sentido, ser carregados de significado.

O que significa dizer que, mais do que a simples utilização de números, a exposição de dados quantitativos deve transmitir informações passíveis de interpretação, inclusive no que se refere aos meios escolhidos para a exposição das informações, como a utilização de gráficos, tabelas, e elementos que auxiliem a uma melhor visualização dos dados expostos, não devendo ser apenas uma contagem de ocorrências. É aconselhável fazer breves explicações sobre o que se trata cada item exposto, pois pouco valem os dados quantitativos se não estiver explicito do que se trata, de forma contundente e informativa. Seguindo esses passos, é possível fazer com que os relatórios possam servir de fato como verdadeiros instrumentos de desempenho de uma Unidade de Informação.

\section{CONCLUSÃO}

Considerando todos os aspectos que foram abordados neste estudo, desde o Planejamento até a elaboração de relatórios, entende-se que o relatório surge como uma ferramenta descritiva resultante de um processo de ações estratégicas. O relatório faz parte do encadeamento de atividades que levam a execução de atos para o alcance das metas organizacionais definidos pelo Planejamento. O relatório é um instrumento de grande importância no que diz respeito a uma real visualização da organização, o que deve permitir a análise dos seus dados para servir de referencial para a elaboração de novos Planejamentos.

Desta forma, entende-se que o relatório faz parte de um ciclo contínuo onde: depois do período da execução de ações previstas em um Planejamento, deve-se avaliar as ações para assegurar-se se estas estão congruentes com o instrumento, o que resulta na elaboração de relatórios. Para que seja feito um novo Planejamento, espera-se que haja uma análise dos relatórios produzidos na avaliação, a fim de verificar quais metas foram cumpridas ou não, para que se possa trabalhar as metas que não foram atingidas e vislumbrar novas metas a serem cumpridas, representando, assim, um ciclo como pode ser observado no gráfico abaixo:

Figura 1 - Ciclo da elaboração do relatório

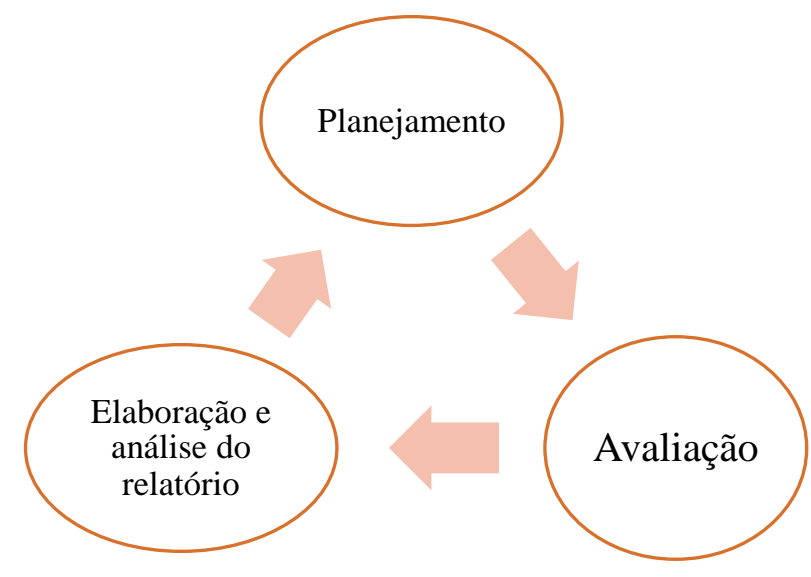

Fonte: Elaborado pela autora

Entende-se, pois, que a elaboração de relatórios não deve ser negligenciada, visto que os dados apresentados em sua estrutura devem ser reflexos do funcionamento de uma organização, e a escassa disponibilidade de dados pode influenciar significativamente na eficácia do Planejamento da instituição.

A análise dos relatórios Anuais do NIB no quesito acervo levou as pesquisadoras a acreditarem que não há um critério contundente para a sua elaboração, o que impossibilita uma melhor análise dos dados referentes ao acervo, que, para os fins deste estudo, gerou a seguinte conclusão:os relatórios anuais de 


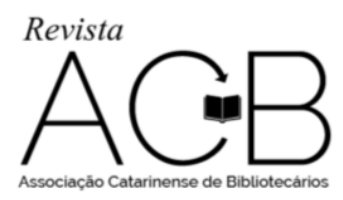

O uso de relatórios anuais de atividades como instrumento de avaliação do acervo das bibliotecas que compõem o Núcleo Integrado de Bibliotecas a Universidade Federal do Maranhão no período de 2008 a 2012 - Cláudia Maria Pinho de Abreu Pecegueiro e Alessandra Gomes Melo Aguiar Freitas

atividades do Núcleo Integrado de bibliotecas da UFMA se constituem como fontes de informações que permitem a análise do funcionamento do Núcleo em cada estágio determinado. Mas, no que se referem às atividades ocorridas no acervo das bibliotecas integrantes do NIB/UFMA durante o período de implementação do Reuni, encontra-se uma dificuldade para a análise dos eventos abordados nos relatórios uma vez que é percebida uma escassez de dados e de suas correlações, impossibilitando uma melhor visualização dos fatos ocorridos no setor. As informações contidas nos relatórios anuais de atividades do NIB/UFMA no quesito acervo podem contribui para o Planejamento do setor, porém, de maneira muito superficial visto que suas informações não são claras nem completas, deixando muitos espaços vazios, dificultando a sua análise.

Conclui-se, finalmente, que os relatórios, de forma geral, são uma importante ferramenta no processo de gestão, explicitando dados referentes à execução de atividades a um dado período de tempo representando a realidade da organização. Mesmo que os dados contidos no relatório não sejam suficientemente claros, é possível emitir juízos de valor a respeito dos aspectos abordados nos referidos documentos, o que mostra a importância desse instrumento, que, de uma forma ou de outra, quando estão disponíveis, fornecem valiosas informações sobre o funcionamento e a realidade da organização.

\section{AGRADECIMENTOS}

À Bibliotecária Regycleia Botelho, pela solícita e eficiente co-orientação, pela disponibilização dos documentos analisados, pelo auxílio nos momentos de dúvida, pelo tempo desprendido para as orientações e pela amizade.

\section{REFERÊNCIAS}

ALMEIDA, Maria Christina Barbosa de. Planejamento de bibliotecas e serviços de informação. 2.ed. rev. e amp. Brasília, DF: Briquet de Lemos, 2005.

ASSOCIAÇÃO BRASILEIRA DE NORMAS TÉCNICAS. NBR: 10719: apresentação de relatórios técnico-científicos. Rio de Janeiro, 1989.

BARBALHO, Célia Regina Simonetti; BERAQUET, Vera Silvia Marão. Planejamento estratégico para unidades de informação. São Paulo: Polis, 1995.

BARCELOS, M. E. A. S.; GOMES, M. L. B. M. Preparando sua biblioteca para aavaliação do MEC. In: SEMINÀRIO NACIONAL DE BIBLIOTECAS UNIVERSITÁRIAS, 8., 2004. Anais... Natal: SNBU, 2004.

CHIAVENATO, Idalberto. Administração geral e pública. 2. ed. Rio de Janeiro: Elsevier, 2008.

INSTITUTO FEDERAL DE RORAIMA. Plano de desenvolvimento institucional. IFRR: Roraima, 2014.

INSTITUTO NACIONAL DE ESTUDOS E PESQUISAS EDUCACIONAIS ANÍSIO TEIXEIRA. Instrumento de Avaliação de Cursos de Graduação:presencial e a distância. Brasília, DF: INEP, 2015. Disponível em:

<http://download.inep.gov.br/educacao_superior/avaliacao_cursos_graduacao/instrumentos/2015/instrum ento_cursos_graduacao_publicacao_agosto_2015.pdf, >. Acesso em 20 jul. 2016.

INSTITUTO NACIONAL DE ESTUDOS E PESQUISAS EDUCACIONAIS ANÍSIO TEIXEIRA. Sistema Nacional de avaliação da Educação Superior:da concepção à regulamentação. 2. ed. Brasília, DF: INEP, 2004.155p. Disponível em: 〈http://http://www.usjt.br/avaliacao_inst/arquivos/sinaes.pdf〉. Acesso em 10 maio 2015. 


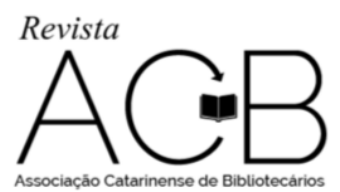

O uso de relatórios anuais de atividades como instrumento de avaliação do acervo das bibliotecas que compõem o Núcleo Integrado de Bibliotecas a Universidade Federal do Maranhão no período de 2008 a 2012 - Cláudia Maria Pinho de Abreu Pecegueiro e Alessandra Gomes Melo Aguiar Freitas

LANCASTER, F. W. A avaliação de serviços em bibliotecas. Brasília, DF: Briquet de Lemos Livros, 2004

LEMOS, Antonio Agenor Briquet de; MACEDO, Vera Amália Amarante. A posição da biblioteca na Organização operacional da Universidade.Revista de Biblioteconomia, Brasília, vol. 2, n. 2, jul./dez. 1974. Disponível em: <http://www.brapci.inf.br/_repositorio/2011/04/pdf_d41a265530_0016328.pdf>. Acesso em 29 março 2015.

LIMA, A. J. A Aplicabilidade de planejamento estratégico em bibliotecas: uma apreciação crítica. Universidade \& Desenvolvimento, Florianópolis, v.3, n.1, p.8-24, abr. 1996.

LUBISCO, Nídia M. L. (Org.). biblioteca universitária: elementos para o planejamento, avaliação e gestão. Salvador: EDUFBA, 2011.

ROTHEN, José Carlos. Ponto e contraponto na avaliação Institucional: análise dos documentos de implantação do SINAES.Educação: Teoria e Prática. Rio Claro, v. 15, n.27, p. 119-137, jul./dez. 2006, p. 119 - 137. Disponível em: 〈http://rothen.pro.br/documentos/teoriaepratica;pontoecontraponto7639.pdf〉. Acesso em 07 dez. 2015.

UNIVERSIDADE FEDERAL DO MARANHÃO. Relatório anual de atividades do NIB. São Luís: UFMA, 2008.

Relatório anual de atividades do NIB. São Luís: UFMA, 2009.

Relatório anual de atividades do NIB. São Luís: UFMA, 2010.

. Relatório anual de atividades do NIB. São Luís: UFMA, 2011.

Relatório anual de atividades do NIB.São Luís: UFMA, 2012.

VALENTIM, Marta. Tipos de Planejamento. Faculdade de Filosofia e Ciências: Marília, 2014.

Disponível em: <http://www.valentim.pro.br/Slides/Planejamento_Arq/Tipos_Planejamento.pdf >. Acesso em 16 dez. de 2014.

VERGUEIRO, Waldomiro. Desenvolvimento de coleções. São Paulo: Polis, 1989.

\title{
THE USE OF ANNUAL ACTIVITY REPORTS AS EVALUATION TOOLS OF THE LIBRARIES COLLECTION THAT MAKE UP THE INTEGRATED CORE OF THE FEDERAL UNIVERSITY OF MARANHÃO LIBRARIES FROM 2008 AT 2012
}

\begin{abstract}
Study on the report as a management tool capable of serving as activities Assessment instrument. Aims to identify, through the analysis of the Annual Integrated Core activities of the Federal University of Maranhão Libraries Reports (NIB / UFMA) if it provides enough information to assist in the process of Evaluation and Planning Libraries NIB / UFMA the Acquis sector period 2008 to 2012. It uses as methodology Documentary research, as well as bibliographic research. It concludes by noting that the annual reports of activities of the NIB / UFMA are important sources of information, however, very superficial, preventing a greater understanding of the data.
\end{abstract}

Keywords: Library Management. University Library. Report. Federal University of Maranhão.

RECEBIDO EM: 28-06-2016

ACEITO EM: 03-04-2017 